\title{
A NOTE ON CLARKSON'S INEQUALITY IN THE REAL CASE
}

\section{Hiroyasu Mizuguchi AND KiCHI-SUKE SAITO}

Abstract. We present an elementary proof of the generalized Clarkson's inequality in the real case.

\section{REFERENCES}

[1] J. A. Clarkson, Uniformly convex spaces, Trans. Amer. Math. Soc., 40 (1936), 396-414.

[2] K. KuRIYAma, M. MiYAgi, M. OKADA AND T. MiYoshi, Elementary proof of Clarkson's inequalities and their generalization, Memories of the Faculty of Engineering, Yamaguchi Univ., 48 (1997), $119-125$.

[3] L. Maligranda And N. Sabourova, On Clarkson's inequaity in the real case, Math. Nachr., 280 (2007), 1363-1375.

[4] K. Mitani, K.-S. Saito And T. Suzuki, On the calculation of the James constant of Lorentz sequence spaces, J. Math. Anal. Appl., 343 (2008), 310-314.

[5] K. Mitani AND K.-S. SAito, Dual of two dimensional Lorentz sequence spaces, Nonlinear Analysis, 71 (2009), 5238-5247. 